ISSN: 0120-131X • ISSN: 2389-9980 (en línea) | Vol. 46 | No. 105 | Enero-junio • 2019 | pp. 1-28

Cuestiones Teológicas | Medellín-Colombia

Cómo citar este artículo en APA: López-Corps, M. (2019). Celebrando la peculiaridad del domingo. Cuestiones Teológicas, 46 (105), 1-28. doi: http://dx.doi.org/10.18566/cueteo.v46n105.a01

Fecha de recepción: 29.10.2018 Fecha de aceptación: 10.12 .2018

\title{
Celebrando \\ LA PECULIARIDAD DEL DOMINGO
}

\author{
Celebrating the Peculiarity of Sunday \\ Comemorar a peculiaridade do domingo
}

Manuel G. López-Corps ${ }^{\mathrm{I}}$

1 Doctor en Sagrada Liturgia por el Pontificio Instituto San Anselmo de Roma. Catedrático de la Universidad Eclesiástica San Dámaso, España. Correo electrónico: mcorps@hotmail.com 


\section{Resumen}

Este artículo propone asuntos teológicos y propuestas pastorales acerca del Domingo y la celebración de la Eucaristía, la fiesta primordial de los cristianos, a partir de la Carta Apostólica Dies Domine, del Papa Juan Pablo II, destacando la Plegaria central del domingo: la anáfora eucarística, los elementos catequéticolitúrgicos de algunos domingos peculiares, con el propósito de aprender a vivir según el domingo.

Palabras clave: Liturgia, Teología del Domingo, Celebración del Domingo, Recomendaciones pastorales.

\section{Abstract}

The article considers theological issues and pastoral strategies regarding Sunday and the celebration of Eucharist, the primordial feast of Christians, based on the Apostolic Letter Dies Domine, by pope John Paul II. Thus, with the purpose of learning how to live according to the celebration of Sunday, the article highlights the central Prayer of Sunday: Eucharistic anaphora and catechetical-liturgical elements of some special Sundays.

Key Words: Liturgy, Theology of Sunday, Celebration of Sunday, Pastoral Strategies.

\section{Resumo}

Esse artigo trata assuntos teológicos e propostas pastorais sobre o Domingo e a comemoração da Eucaristia, a festa primordial dos cristãos, segundo a Carta Apostólica Dies Domine do Papa João Paulo II, com o propósito de salientar a plegária central do domingo: a anáfora eucarística, os elementos catequéticolitúrgicos de alguns domingos particulares, a fim de aprender a viver segundo o domingo.

Palavras-chave: liturgia, teologia do domingo, comemoração do domingo, recomendações pastorais. 


\section{Introducción}

La cita evangélica de Mc 14, 22-25 es, quizá, la versión textual más antigua de la Cena del Señor que transmitía la Iglesia madre de Jerusalén ( $C f r$. Mt 26, 26-29). Otra tradición, aquella de Antioquía, la refleja el Apóstol de las gentes a la comunidad de Corinto al inicio de los ańos 50, ańade: "Y así, siempre que comáis este pan y bebáis esta copa, proclamaréis la muerte del Señor hasta que Él vuelva. Por eso, el que coma el pan o beba la copa del Señor indignamente tendrá que dar cuenta del Cuerpo y de la Sangre del Señor" (Cfr. 1 Cor 11, 23-27).

Todos los domingos escuchamos estas palabras que son el corazón de la Plegaria más importante de los cristianos. En efecto, además de enseñarnos a rezar el "Padrenuestro", que repetimos cada día mañana y tarde, Jesucristo, antes de ser llevado a la muerte, pronunció una plegaria de bendición y de acción de gracias sobre el pan y sobre la copa de vino que transformó la realidad de la creación, para transformarnos a los que participamos en esa celebración. Y, así, fiel al mandato de su Señor y con fe en su vuelta, la Iglesia — comunidad de creyentes en el Señor Jesús — lo viene realizando desde sus comienzos apostólicos hasta nuestros días. Y lo hace anhelando un día: "Hasta el día en que beba el vino nuevo en el Reino de Dios". Pero mientras ese día llega, el día definitivo del Señor, cada primer día de la semana, recuerdo y anhelo, proclama la muerte victoriosa de su Señor. ${ }^{2}$

Lo instituido en la Última Cena contiene, en núcleo, todo el Misterio Pascual de Cristo: el que ha sido entregado a la muerte como Cordero, ha sido resucitado con la fuerza del León $(C f r$. Ap 5, 5). La Eucaristía que nos mandó celebrar el Señor, en aquel Jueves Santo, nos hace descubrir — cada primer día de la semana que llamamos "domingo" - al Dominus, al Señor resucitado. ${ }^{3}$ En efecto, en el pan partido reconocemos al Crucificado para

2 Sobre los nombres de nuestra primera fiesta cristiana tenemos un antiguo estudio del magistral B. Botte (1990), Las denominaciones del domingo en la tradición cristiana.

3 "El Señor en ese día, dio al mundo las primicias de la resurrección; en ese día... ordenó celebrar los santos misterios” (Eusebio de Alejandría, Sermón 16, PG 86, 461). 
quitar el pecado del mundo, pero también, al Viviente dador de vida, ya que quien le coma vivirá por Él (Cfr. Jn 6, 57).

No es la única, pero una característica cristiana del domingo es la celebración de la Eucaristía, la Misa. Esa celebración, central para la Iglesia, hace que el primer día de la semana sea memorial; es decir, no solo un recuerdo sino una posibilidad de encuentro con el Resucitado que nos explica las Escrituras, parte para nosotros el pan y hace que arda el corazón al experimentarlo vivo (Cfr. Lc 24). El domingo es un día peculiar por ser el día en que actuó el Señor Dios sacando a Jesús de entre los muertos y constituyéndolo Señor y Mesías (Hech 2, 36). Este único y definitivo acontecimiento no se celebra de manera monótona.

Podríamos decir que no todos los domingos son iguales. Cada cristiano, desde el tiempo de la primera catequesis, hemos aprendido a diferenciar cada domingo por el Evangelio proclamado según su ciclo anual (A, B, C), o según el otro triple ciclo temporal que esté viviendo la Iglesia (<manifestación>: Adviento / Navidad / Epifanía; <oblación>: Cuaresma, Triduo y Cincuentena pascual; y, durante el resto del ańo o tiempo cotidiano de la < divinización > en el tiempo ordinario de nuestra vida: 33/34 semanas) (Cfr. López-Corps, 2009, pp. 297-310). De hecho, muchos identifican la peculiaridad del domingo por el color de las vestiduras ministeriales o por el evangelio proclamado. ${ }^{4}$

4 "Como conclusión de las lecturas de la Sagrada Escritura, la expresión Verbum Domini - Palabra de Dios — nos recuerda la importancia de lo que sale de la boca de Dios. Nos lo hace sentir no como un texto «lejano», sino que por ser inspirado, es palabra viva con la cual Dios nos interpela: nos encontramos en el contexto de un verdadero «diálogo de Dios con su pueblo, en el cual son proclamadas las maravillas de la salvación y propuestas siempre de nuevo las exigencias de la alianza»" (Dies Domini, n. 41).

La liturgia de la Palabra es una parte constitutiva de la Eucaristía (Cfr. SC, n. 56; Dies Domini, nn. 39-41). Nos recogemos en asamblea litúrgica para escuchar lo que el Señor quiere decirnos: a todos y a cada uno. Él habla aquí y ahora, a nosotros que lo escuchamos con fe, creyendo que Él solo tiene palabras de vida eterna, que su palabra es lámpara para nuestros pasos.

Participar en la Eucaristía quiere decir escuchar al Señor con el fin de poner en práctica cuanto nos manifiesta, nos pide, desea de nuestra vida. El fruto de la escucha 
Sin embargo, hay algo que pasa habitualmente muy desapercibido y que, como hemos dicho, es el corazón de la Misa: la Plegaria Eucarística o Anáfora. Podríamos describirla como una oración con "palabra divina" donde se perpetúa la acción del mismo Cristo. Sería, como decimos en nuestro lenguaje coloquial, una oración performativa; es decir, que al enunciarse realiza la acción que significa. Pero, además, los domingos pueden ser peculiares por las acciones que en ellos se realizan. En este campo la Encíclica Dies Domini da pistas interesantes y, de hecho, en muchas parroquias y movimientos cristianos, el domingo - ya vivido y celebrado desde sus primeras vísperas- es el día de la caridad, el día de las obras de misericordia.

Es, también, la jornada en que se convoca a la comunidad o a grupos particulares para charlas de formación (escuela dominical) o para encuentros sociales (comidas con ancianos, parados, gente sola, etc.). Asimismo, se puede vivir el domingo peculiarmente acentuando o subrayando algún aspecto del tiempo litúrgico que se celebra, para después llevar al hogar o a la escuela católica (bendición de la corona de Adviento, del árbol, del pesebre, campañas sociales o colectas en favor de las misiones, pobres, etc.). Todos estos aspectos han sido tratados muy desigualmente.

Ya se ha abordado, de manera prolija, sobre la Palabra de Dios en su proclamación dominical y, también, sobre la dimensión social del Domingo.

de Dios que nos habla cuando en la Iglesia se leen las Sagradas Escrituras ( $C f$ r. SC, n. 7) madura en el vivir cotidiano (Cfr. Mane nobiscum Domine, n. 13).

La actitud de escucha es el principio de la vida espiritual. Creer en Cristo es escuchar su palabra y ponerla en práctica. Es docilidad a la voz del Espíritu Santo, el Maestro interior que nos guía a la verdad completa, no solamente a la verdad del conocer sino también a la verdad del practicar.

Para escuchar al Señor en la liturgia de la Palabra, es necesario tener afinado el oído del corazón. A ello nos prepara la lectura personal de las Sagradas Escrituras, en tiempos y ocasiones programados y no dejados a eventuales recortes de tiempo. $\mathrm{Y}$ a fin de que lo que se ha escuchado en la celebración eucarística no desaparezca de la mente y del corazón al salir de la iglesia, es necesario encontrar modos para extender la escucha de Dios, que nos hace llegar su voz de mil maneras a través de las circunstancias de la vida cotidiana" (Sugerencias y Propuestas de la Congregación para Culto Divino ante la celebración del Año de la Eucaristía, 2005, n. 21). 
Por eso, en esta aportación teológico-pastoral proponemos destacar algunos aspectos menos tratados pero realmente importantes: la Plegaria Eucarística dominical, un breve elenco de propuestas de "domingos peculiares" para, al final, ofrecer pistas o posibilidades para vivir más profundamente el día del Señor.

\section{La fiesta primordial de los cristianos}

Más que una teoría está la existencia de cristianos que, incluso, han dado su vida por la espiritualidad del Domingo: primero y, a la vez, octavo día de la semana. ${ }^{6}$ En efecto, a principios del siglo IV, siendo ilícito el culto cristiano en el Imperio Romano, algunos fieles del Norte de África, que se sentían en la obligación de celebrar el día del Señor, desafiaron la prohibición. Fueron condenados a muerte por declarar que no les era posible vivir sin reunirse para la Eucaristía: sine dominico non possumus. Estos mártires de Abitinia nos enseñan la fidelidad al encuentro con Cristo Resucitado porque todo fiel cristiano tampoco puede vivir sin participar en el Sacramento de la salvación deseando iuxta dominicam viventes, es decir, llevar a la vida lo que se celebra en el día del Señor (Cfr. Sacramentum Caritatis, n. 95). ${ }^{7}$

5 Siempre sin instrumentalizar la liturgia (Cfr. López Martín, 1988, pp. 137-140).

6 "Los días festivos contemplan la alegría como una prenda y un anticipo de la felicidad plena que sólo se alcanzará más allá de las fronteras de este mundo, cuando la lucha dará paso a la paz, los recelos y los odios a la reconciliación, el dolor al consuelo y los esfuerzos de los hombres al descanso de Dios. El domingo es el día primero de la semana, pero es también el octavo día, porque es un don de Dios que anuncia las realidades últimas y definitivas, y permite anticipar todo aquello que es esperado y deseado como futuro. Entre los signos festivos más comunes y todavía expresivos, se encuentran el vestido nuevo o traje de fiesta y la comida abundante y compartida. Son los mismos signos que aparecen en el Evangelio como seńal y exigencia, a la vez, de una vida eterna que, sin embargo, es también proyecto y esperanza realizable que da sentido a la presencia y a la acción de los cristianos en el mundo" (Conferencia Episcopal Española, 1992, n. 27; Cfr. Dies Domini, nn. 23, 26, 33; Cfr. Danielou, 1990, pp. 33-61).

7 En adelante se usa la sigla SC para hacer referencia a este Documento. 
En las Sugerencias y Propuestas ${ }^{8}$ que la Santa Sede hacía para la celebración del Año de la Eucaristía en el año 2005 se acentuaba la importancia del primer día de la semana presentando un apretado compendio. Efectivamente, dicho Documento, de índole teológico-pastoral, al presentar la enseñanza del Concilio Vaticano II, comenzaba señalando que el domingo es "la fiesta primordial" por ser "el fundamento y el núcleo de todo el año litúrgico" (SC, n. 106). ${ }^{9}$ En continuidad con el primer texto magisterial sobre este tema, Dies Domini recogía esta idea de San Juan Pablo II: "Considerando globalmente sus significados y sus implicaciones, [el domingo] es como una síntesis de la vida cristiana y una condición para vivirlo bien" (n. 81). Además, porque "[...] la celebración eucarística es, de hecho, el corazón del domingo" (SP, 2005). Es el día de Cristo Resucitado que trae consigo la memoria de lo que es el fundamento mismo de la fe cristiana ( $C f r$. 1Cor 15, 14-19):

Aunque el domingo es el día de la resurrección, no es solo el recuerdo de un acontecimiento pasado, sino que es celebración de la presencia viva del Resucitado en medio de los suyos. Para que esta presencia sea anunciada y vivida de manera adecuada no basta que los discípulos de Cristo oren individualmente y recuerden en su interior, en lo recóndito de su corazón, la muerte y resurrección de Cristo. [...] Por eso es importante que se reúnan, para expresar así plenamente la identidad misma de la Iglesia, la ekklesía, asamblea convocada por el Señor resucitado (Dies Domini, n. 31).

$8 \quad$ En adelante se usa la sigla SP para hacer referencia a este Documento.

9 La cita es, ya por sí misma, todo un tratado bellísimo y condensado sobre la teología del domingo: "La Iglesia, por una tradición apostólica, que trae su origen del mismo día de la Resurrección de Cristo, celebra el misterio pascual cada ocho días, en el día que es llamado con razón "día del Señor" o domingo. En este día los fieles deben reunirse a fin de que, escuchando la palabra de Dios y participando en la Eucaristía, recuerden la Pasión, la Resurrección y la gloria del Señor Jesús y den gracias a Dios, que los «hizo renacer a la viva esperanza por la Resurrección de Jesucristo de entre los muertos» $(1 \mathrm{Pe}, 1,3)$. Por esto el domingo es la fiesta primordial, que debe presentarse e inculcarse a la piedad de los fieles, de modo que sea también día de alegría y de liberación del trabajo. No se le antepongan otras solemnidades, a no ser que sean de veras de suma importancia, puesto que el domingo es el fundamento y el núcleo de todo el año litúrgico" (SC, n. 106). 
Como sucedía con los mártires de Abitinia, también nosotros reconocemos el nexo entre la manifestación del Resucitado y la Eucaristía en:

[...] la narración de los discípulos de Emaús (cf. Lc 24,13-35), guiados por Cristo mismo para entrar íntimamente en su misterio a través de la escucha de la Palabra y la comunión del «Pan partido» (cf. Mane nobiscum Domine). Los gestos realizados por Jesús: «Él tomó el pan, lo bendijo, lo partió y se lo dio» (Lc 24,30), son los mismos que Él efectuó en la Última Cena y que incesantemente realiza, por medio del sacerdote, en nuestras eucaristías" (SP, 2005).

Si realmente la Iglesia no puede vivir sin el Domingo, este día ha de ser preparado de manera adecuada y sentido como tal. ${ }^{10}$ Evidentemente, no solo es el primero en cada semana - y así hemos de publicarlos en los calendarios cristianos - sino que es de mayor duración: este día tiene más horas que el resto de los días de la semana. ${ }^{11}$ No se trataría, simplemente, en asegurar el hecho de su celebración sino también en el cómo celebrativo pues

[...] el carácter propio de la Misa dominical y la importancia que ésta reviste para la vida cristiana exigen que se prepare con especial cuidado, de modo que se experimente como una epifanía de la Iglesia (cf. Dies Domini, 34-36; Ecclesia de Eucharistia, 41, Novo Millennio Ineunte, 36) y se distinga como celebración alegre y melodiosa, activa y participada (cf. Dies Domini, 50-51) (SP, 2005).

Aquí entraría el papel del Grupo o Comisión de liturgia, el ministerio ordenado del Diácono, el ministerio de los coros, las funciones que desempeñan, los lectores/as, salmista, acólitos, etc. Todo para asegurar una

10 En las dos últimas ediciones del Misal se ha dado mayor énfasis al día del Señor: se ofrecen varios formularios para la bendición y aspersión del agua al principio de la misa dominical — para no realizar el Acto penitencial habitualmente en el primer día de la semana— donde se habla del domingo como "día consagrado al Señor" o "día memorial de la resurrección".

11 Tras la hora de Nona del sábado comienza el domingo; no existe litúrgicamente la "tarde del sábado"; estas primeras horas del día del Señor son tan domingo como las de su mañana. Esto se manifiesta en la celebración de la Eucaristía. 
participación activa, consciente y fructuosa a la que todo cristiano tiene derecho por el Bautismo, y así poder manifestar la realidad de la Iglesia que celebra en el domingo el recuerdo de la Resurrección y anhela la venida gloriosa del Señor desde los cielos. ${ }^{12}$

\section{La Plegaria central del domingo: la anáfora eucarística}

En la celebración dominical de la Misa,

[...] muchos siguen viviendo la consagración como algo en sí mismo, separado del resto de la Plegaria Eucarística [....algo así como si esta solo fueran] oraciones que enmarcan la consagración. Esto es el resultado de unas acaloradas disputas medievales sobre el santo Sacramento que llevaron a los teólogos a responder con precisión casi matemática cómo se realiza, en qué preciso momento acontece, cuáles son las palabras que la producen. Todo ello ha llevado, en el segundo milenio, a descuidar el estudio y la espiritualidad de la Plegaria Eucarística (Giraudo, 2012, p. 10).

Hoy, siguiendo el surco de la gran tradición cristiana ${ }^{13}$, la Ordenación

12 Sobre la espiritualidad del día del Señor, véase: G. Florio, La domenica - Perché andiamo a celebrare?.

13 Sobre la institución de la Eucaristía en la última Cena: "Sucedió en el contexto de una cena ritual con la que se conmemoraba el acontecimiento fundamental del pueblo de Israel: la liberación de la esclavitud de Egipto. Esta cena ritual, relacionada con la inmolación de los corderos (Ex 12,1- 28.43-51), era conmemoración del pasado, pero, al mismo tiempo, también memoria profética, es decir, anuncio de una liberación futura. En efecto, el pueblo había experimentado que aquella liberación no había sido definitiva, puesto que su historia estaba todavía demasiado marcada por la esclavitud y el pecado. El memorial de la antigua liberación se abría así a la súplica y a la esperanza de una salvación más profunda, radical, universal y definitiva. Éste es el contexto en el cual Jesús introduce la novedad de su don. En la oración de alabanza, la Berakah, da gracias al Padre no sólo por los grandes acontecimientos de la historia pasada, sino también por la propia «exaltación». Al instituir el sacramento de la Eucaristía, Jesús anticipa e implica el Sacrificio de la cruz y la victoria de la resurrección. Al mismo tiempo, se revela como el verdadero cordero 
General del Misal Romano ${ }^{14}$ enseña que:

[...] en la última Cena, Cristo instituyó el sacrificio y el banquete pascuales. Por estos misterios el sacrificio de la cruz se hace continuamente presente en la Iglesia, cuando el sacerdote, representando a Cristo Señor, realiza lo mismo que el Señor hizo y encomendó a sus discípulos que hicieran en memoria de Él. Cristo, pues, tomó el pan y el cáliz, dio gracias, partió el pan, y los dio a sus discípulos, diciendo: «Tomad, comed, bebed; esto es mi Cuerpo; éste es el cáliz de mi Sangre. Haced esto en conmemoración mía». Por eso, la Iglesia ha ordenado toda la celebración de la Liturgia Eucarística con estas tres partes que responden a las palabras y a las acciones de Cristo, a saber:

1) En la preparación de los dones se llevan al altar el pan y el vino con agua, es decir, los mismos elementos que Cristo tomó en sus manos.

2) En la Plegaria Eucarística se da gracias a Dios por toda la obra de la salvación y las ofrendas se convierten en el Cuerpo y en la Sangre de Cristo.

3) Por la fracción del pan y por la Comunión, los fieles, aunque sean muchos, reciben de un único pan el Cuerpo, y de un único cáliz la Sangre del Señor, del mismo modo como los Apóstoles lo recibieron de las manos del mismo Cristo (n. 72).

En la normativa del Misal se describe esta Plegaria Eucarística, oración de bendición — berakáh — y de agradecimiento — todá-, como "el centro y la cumbre de toda la celebración" (OGMR, n. 78; Cfr. N. 30) pues,

inmolado, previsto en el designio del Padre desde la creación del mundo, como se lee en la primera Carta de San Pedro (cf. 1,18-20). Situando en este contexto su don, Jesús manifiesta el sentido salvador de su muerte y resurrección, misterio que se convierte en el factor renovador de la historia y de todo el cosmos. En efecto, la institución de la Eucaristía muestra cómo aquella muerte, de por sí violenta y absurda, se ha transformado en Jesús en un supremo acto de amor y de liberación definitiva del mal para la humanidad" (SC, n. 10).

14 En adelante se usa la sigla OGMR para hacer referencia a este Documento. 
[...] ciertamente es una oración de acción de gracias y de santificación. El sacerdote invita al pueblo a elevar los corazones hacia el Señor, en oración y en acción de gracias, y lo asocia a sí mismo en la oración que él dirige en nombre de toda la comunidad a Dios Padre, por Jesucristo, en el Espíritu Santo. El sentido de esta oración es que toda la asamblea de los fieles se una con Cristo en la confesión de las maravillas de Dios y en la ofrenda del sacrificio (OGMR, n. 78).

Y además,

El pueblo se asocia al sacerdote en la fe y por medio del silencio, con las intervenciones determinadas en el curso de la Plegaria Eucarística, que son las respuestas en el diálogo del Prefacio, el Santo, la aclamación después de la consagración y la aclamación <Amén> después de la doxología final, y también con otras aclamaciones aprobadas, tanto por la Conferencia de Obispos, como por la Sede Apostólica (OGMR, n. 147). ${ }^{15}$

\section{Secciones de la Plegaria}

El mismo documento presenta el elenco de los principales elementos de que consta la Plegaria Eucarística:

a) Acción de gracias — que se expresa especialmente en el Prefacio-, en la cual el sacerdote, en nombre de todo el pueblo santo, glorifica a Dios Padre y le da gracias por toda la obra de salvación o por algún aspecto particular de ella, de acuerdo con la índole del día, de la fiesta o del tiempo litúrgico.

b) Aclamación: con la cual toda la asamblea, uniéndose a los coros celestiales, canta el Santo. Esta aclamación, que es parte de la misma Plegaria Eucarística, es proclamada por todo el pueblo juntamente con el sacerdote.

15 Es una lástima dejar pasar las diversas ediciones del Misal sin incorporar alguna aclamación más, en el interior de la Plegaria, para la intervención del pueblo sacerdotal ante la segunda epíclesis. 
c) Epíclesis: con la cual la Iglesia, por medio de invocaciones especiales, implora la fuerza del Espíritu Santo para que los dones ofrecidos por los hombres sean consagrados; es decir, se conviertan en el Cuerpo y en la Sangre de Cristo, y para que la víctima inmaculada que se va a recibir en la Comunión sirva para la salvación de quienes van a participar en ella. ${ }^{16}$

d) Narración de la institución y consagración: por las palabras y por las acciones de Cristo se lleva a cabo el sacrificio que el mismo Cristo instituyó en la última Cena, cuando ofreció su Cuerpo y su Sangre bajo las especies de pan y vino, y los dio a los Apóstoles para que comieran y bebieran, dejándoles el mandato de perpetuar el mismo misterio. $^{17}$

e) Anámnesis: por la cual la Iglesia, al cumplir el mandato que recibió de Cristo por medio de los Apóstoles, realiza el memorial del mismo Cristo, renovando principalmente su bienaventurada pasión, su gloriosa resurrección y su ascensión al cielo.

f) Oblación: por la cual, en este mismo memorial, la Iglesia, principalmente la que se encuentra congregada aquí y ahora, ofrece al Padre en el Espíritu Santo la víctima inmaculada. La Iglesia, por su parte, pretende que los fieles, no solo ofrezcan la víctima inmaculada, sino que también aprendan a ofrecerse a sí mismos, y día a día se perfeccionen, por la mediación de Cristo, en la unidad con Dios y entre ellos, para que finalmente, Dios sea todo en todos.

g) Intercesiones: por las cuales se expresa que la Eucaristía se celebra en comunión con toda la Iglesia, tanto con la del cielo, como con la de la tierra; y que la oblación se ofrece por ella misma y por todos sus

16 Convendría tener en cuenta esta afirmación: "La transformación del pan y del vino en el Cuerpo y la Sangre del Señor no es un fin en sí misma, sino que se orienta a hacer la Iglesia, es decir a transformarnos en el Cuerpo místico a medida que vamos celebrando nuestras misas [...] El último término de la celebración eucarística no es el "Cristo sacramental"; el término último y el fin propio de la acción eucarística es el <Cristo eclesial>, es decir, la edificación de la Iglesia” (OGMR, nn. 11, 66).

17 La Plegaria Eucarística II para las misas por diversas necesidades habla de la ofrenda de la Iglesia "en la que se hace presente el sacrificio pascual de Cristo". La Eucaristía hace "presente el Sacrificio redentor de la Cruz, perpetuándolo sacramentalmente" (Ecclesia de Eucharistia, n. 37). 
miembros, vivos y difuntos, llamados a participar de la redención y de la salvación adquiridas por el Cuerpo y la Sangre de Cristo.

h) Doxología final: por la cual se expresa la glorificación de Dios, que es afirmada y concluida con la aclamación «Amén» del pueblo ( $C f$ r. OGMR n. 79).

\section{Catequesis mistagógica}

Estos elementos — fundamentales para entender la oración anáforicahabrá que tenerlos en cuenta a la hora de exponer catequéticamente que esta oración es la central del domingo: "Las diversas Plegarias eucarísticas que hay en el Misal nos han sido transmitidas por la tradición viva de la Iglesia y se caracterizan por una riqueza teológica y espiritual inagotable. Se ha de procurar que los fieles las aprecien" (SC, n. 48). La razón es obvia: la Plegaria Eucarística es el "corazón" de toda la Misa; comienza con el diálogo "Levantemos el corazón” y concluye con el "Amén” solemne. ${ }^{18}$ En la catequesis eucarística se ha de subrayar primero la importancia y, después, la unidad de la Plegaria que en la tradición se ha llamado Canon —en Occidente_, o Anáfora — en Oriente—. La Plegaria es, toda ella, una misma oración aunque esté compuesta por diversos elementos: Prefacio, Invocación del Espíritu, Consagración, Memorial, Ofrenda, Intercesiones, etc. O haya distintas intervenciones en su seno: "Santo", respuesta a la monición "Este es el misterio de la fe", otras posibles aclamaciones y el "Amén" final. ${ }^{19}$

18 Ya hemos señalado que en las dos últimas ediciones del Misal se ha dado mayor énfasis al día del Señor: se han añadido más Prefacios — uno de ellos sobre la realidad mistérica del domingo- $-\mathrm{y}$, además, unas glosas o embolismos para intercalar en la Plegaria Eucarística de cuyas ideas se puede obtener una primera catequesis mistagógica: nos reunimos en comunión "para celebrar el día en que Cristo ha vencido a la muerte y nos ha hecho partícipes de su vida inmortal".

19 Cada domingo, el sacerdote en el transcurso de la Plegaria dirigida a Dios Padre se dirige al pueblo con esta monición mistagógica «Este es el Misterio de la fe» cuya respuesta puede variar según los domingos del Año litúrgico (p.e.: la primera respuesta del pueblo para los tiempos de Adviento y Navidad; la segunda para el Tiempo ordinario; la tercera para Cuaresma, Triduo y Cincuentena): “Con esta expresión, pronunciada inmediatamente después de las palabras de la consagración, el sacerdote proclama el misterio celebrado y manifiesta su admiración ante la conversión sustancial del pan y el vino en el cuerpo y la sangre del Señor Jesús, una 
Esta Plegaria eclesial pone palabras a la plegaria del mismo Jesús en la Última Cena cuando "pronunció una oración de acción de gracias y de bendición” (Cfr. Mt 26, 26; Mc 14, 22; Lc 22, 19) para después partir el pan y entregar la copa como su Cuerpo y Sangre. El sentido profundo de esta Plegaria — reproduciendo la misma oración de Cristo al Padre- es realizar la comunión con Cristo y entre nosotros por la transformación que realiza el Espíritu Santo para gloria de Dios. También en la última Cena Jesús ha rogado por los suyos ( $C f$ r. Jn 17), de ahí el matiz intercesor de la plegaria cristiana - "por ellos"- Por esta razón, en la Plegaria anafórica se pide tanto el cambio del pan y del vino como nuestro propio cambio a fin de ser "cristificados": hombres y mujeres entregando la vida por amor agradecido a Dios, en servicio a los hermanos, forjando comunión entre unos y otros en bien del mundo (segunda epíclesis). ${ }^{20}$

La Plegaria Eucarística —en la tradición cristiana - es una oración trinitaria, solemne, sublime, poética, ritual y regulada, que contiene la alabanza por excelencia al Padre, el memorial del Misterio Pascual de Cristo y la invocación al Espíritu Santo Creador (Cfr. Fernández Caballero, 2000). Por lo tanto, no puede realizarse ni escucharse de manera rutinaria. En la catequesis mistagógica - partiendo del signo y entrando en el significado- y en las eventuales moniciones que se hagan cada domingo antes de su proclamación, se debe tender hacia un equilibrio que lleve a valorar tanto el texto, el silencio,

realidad que supera toda comprensión humana. En efecto, la Eucaristía es «misterio de la fe» por excelencia: es el compendio y la suma de nuestra fe. La fe de la Iglesia es esencialmente fe eucarística y se alimenta de modo particular en la mesa de la Eucaristía. La fe y los sacramentos son dos aspectos complementarios de la vida eclesial. La fe que suscita el anuncio de la Palabra de Dios se alimenta y crece en el encuentro de gracia con el Señor resucitado que se produce en los sacramentos: la fe se expresa en el rito y el rito refuerza y fortalece la fe. Por eso, el Sacramento del altar está siempre en el centro de la vida eclesial; gracias a la Eucaristía, la Iglesia renace siempre de nuevo. Cuanto más viva es la fe eucarística en el Pueblo de Dios, tanto más profunda es su participación en la vida eclesial a través de la adhesión consciente a la misión que Cristo ha confiado a sus discípulos. La historia misma de la Iglesia es testigo de ello. Toda gran reforma está vinculada de algún modo al redescubrimiento de la fe en la presencia eucarística del Señor en medio de su pueblo" (SC, n. 6).

20 Esta es la gran petición al Espíritu que la Iglesia hace para todos sus miembros en la reunión dominical cada vez que inicia una semana. 
así como las posturas y aclamaciones de los fieles. De esta manera, aprendiendo el arte de celebrar, pasando por la liturgia de cada domingo (un día del Seńor, un día para el Señor, un día hacia el Señor) se entre en la vivencia del misterio y anhelando la liturgia del "Domingo sin ocaso". ${ }^{21}$

\section{Diversidad celebrativa}

En el Rito Romano, durante siglos, se ha rezado solo con una única Plegaria, el Canon; sin embargo, la diversidad de anáforas - fruto de la renovación conciliar - ha puesto de manifiesto la riqueza del Misterio de Cristo con la diversidad eucológica que la Iglesia posee para expresar la acción de gracias a Dios y la bendición. En efecto, en el Misal del Pablo VI — tanto en latín como en español — hay trece Plegarias diferentes: cuatro en el Ordinario y el resto en el apéndice. Sería de desear que nosotros, cada domingo, pudiésemos elevar el corazón con la escucha orante de estas diversas anáforas.

Para una adecuada atención y comprensión de este texto sagrado, ya la Carta Eucharistiae participationem (n. 8), y, ahora, la tercera edición del Misal recuerdan que el presidente de la celebración tiene la facultad de introducir la Plegaria Eucarística con breves palabras. Con esta monición se pueden proponer a los fieles "las razones de la misma acción de gracias, de suerte que la comunidad pueda sentir su propia vida íntimamente enmarcada en la historia de la salvación y pueda cosechar mayores frutos de la celebración de la Eucaristía” (OGMR, n. 31).22

Ahora bien, lo interesante es orar con los trece textos que propone el Misal. Para ello, no hay criterios estrictos o predeterminados sino que, sobre todo, han de ser razones de orden pastoral las que determinen la elección de una u otra anáfora. Proponemos, aquí, algunas sugerencias o líneas directrices generales para el domingo:

21 Una síntesis muy valiosa en: J. Castellano (1992), La espiritualidad del domingo. Teología, mistagogía, compromiso.

22 Un método expresivo para subrayar la importancia de la anáfora es cantar, cada domingo, el Prefacio o, al menos, el diálogo inicial. Se ha de recordar que una vez iniciada la Plegaria ya no se pueden hacer explicaciones o moniciones (Cfr. OGMR, n. 31), p. e.: "Ahora nos ponemos de rodillas", "Estemos atentos", etc. 
1. La Plegaria Eucarística primera, o Canon romano, que se puede usar siempre, se dirá preferentemente en los días que tienen asignados "Reunidos en comunión" propio, o en las misas que tienen su particular "Acepta, Señor, en tu bondad". Puede usarse cualquier domingo, especialmente, en aquellos que coincidan con las celebraciones de los Apóstoles y Santos de quienes se hace mención en dicha Plegaria ( $C f r$. OGMR, n. 365a). Los Prefacios dominicales que pueden usarse con esta Plegaria, como con las dos siguientes, ayudan a centrar la teología y la espiritualidad del día del Señor.

2. La segunda Plegaria Eucarística, caracterizada por su concisión, conviene solo algún domingo, ya que está prevista, fundamentalmente, para los días laborables, las misas con jóvenes o para pequeños grupos. Su sencillez constituye una buena base inicial para la catequesis sobre los varios elementos de la anáfora. Tiene un prefacio propio que normalmente debería ser usado junto con el resto de la Plegaria; sin embargo, puede ser sustituido por otro análogo, es decir, que exprese de una manera concisa el misterio de la salvación (Cfr. OGMR, n. 365b).

3. La tercera Plegaria Eucarística, inspirada en la tradición hispanogalicana, puede usarse con cualquiera de los prefacios. Su uso se recomienda en cualquier domingo; ofrece la posibilidad de nombrar el santo del día ( $C f r$. OGMR, n. 365c).

4. La cuarta Plegaria Eucarística —inspirada en la tradición orientalpresenta un compendio de la historia de la salvación en una unidad temática. Su prefacio es invariable. Los días más indicados para su uso serían los domingos "durante el ańo". En esta Plegaria, por razón de su propia estructura, no se puede introducir una mención o fórmula peculiar por un difunto ( $C f$ r. OGMR, n. 365d).

Las dos Plegarias Eucarísticas de la Reconciliación son muy adecuadas durante el tiempo de Cuaresma. ${ }^{23}$ La Plegaria para las «Misas por diversas

23 Dice la propia rúbrica de la Plegaria I para la Reconciliación: "Esta Plegaria eucarística forma un todo con su Prefacio, el cual normalmente no puede cambiarse, y, por consiguiente, no puede decirse cuando está prescrito un prefacio propio. En los otros casos puede decirse, pero siempre con su prefacio o algún otro que haga referencia a la penitencia o a la conversión, como, por ejemplo, los de Cuaresma”.

La rúbrica de la Plegaria II para la Reconciliación prescribe: "Esta plegaria eucarística 
necesidades», con cuatro variantes, tiene su puesto en esas celebraciones, generalmente solo del tiempo Ordinario, en las que se tienen presentes las diversas situaciones de la Iglesia y del mundo (unidad, paz, perdón, etc.). Por fin, aquellas otras tres Plegarias son — como su nombre lo indica— para las celebraciones con nińos (misas de catequesis, primera comunión, etc.) ${ }^{24}$.

Hemos citado ya la Exhortación que dice que la importancia de la Plegaria "merece ser subrayada adecuadamente" (SC, n. 48). Esto se lograría con el uso ordenado de las anáforas en los diversos domingos que contribuiría a dar a la celebración dominical un tono peculiar.

\section{Elementos catequético-litúrgicos de algunos domingos peculiares}

Presentamos solo un elenco de celebraciones — a manera de sugerencias pastorales - que pueden tener lugar dentro de la misa del domingo y que dan a esta un acento particular. Muchas de ellas se encuentran con sus sugerencias y rúbricas en el mismo Misal Romano, en el Ritual de Bendiciones y en el Ceremonial:

- $\quad$ Bendición de la Corona de Adviento ${ }^{25}$ (1er. Domingo).

- Bendición del árbol de Pascuas o de Navidad ${ }^{26}$ (3er. Domingo Adviento).

forma un todo con su prefacio, el cual nunca puede cambiarse. Por consiguiente, no puede decirse cuando está prescrito un prefacio propio. En los otros casos puede decirse, incluso cuando las rúbricas prescriban un Prefacio del tiempo": Cfr. http:// www.iglesia.cl/conali/boletin/conali_146.pdf.

24 También podrían ser utilizadas en asambleas dominicales donde el número de niños es relativamente considerable.

$25 \mathrm{Al}$ comienzo de la celebración en sustitución del Acto penitencial. La temática de la Corona de luces del Adviento es de una gran riqueza catequética: el primer domingo los personajes son Adán y Eva y la temática es el pecado; el segundo, los patriarcas y matriarcas con la alianza; el tercero, los profetas y profetisas de Moisés y Elías a Juan el Bautista con la esperanza alegre de la salvación por la conversión; y, el cuarto, María, hija de Sión, madre de esperanza en las promesas.

26 Al concluir la Misa del Domingo "Gaudete" la bendición e iluminación festiva del "Árbol de la Vida" prepara la Navidad inminente. 
- Bendición de las familias ${ }^{27}$ (Domingo de la Sagrada Familia).

- Bendición de los hogares el domingo más cercano a Epifanía. ${ }^{28}$

- Anuncio de la fecha de Pascua ${ }^{29}$ (día de Epifanía o Domingo previo).

- Bendición del agua [y de la sal] ${ }^{30}$, aspersión al pueblo y, eventualmente, celebración de bautismos de niños (Domingo del Bautismo del Señor).

- El Canto de las Letanías de los santos ${ }^{31}$ (1er. Domingo de Cuaresma) al inicio de la Misa.

- Domingos de la Santa Cuaresma. ${ }^{32}$

- Escrutinios y entregas a los catecúmenos ${ }^{33}$ (Domingos III, IV y V de Cuaresma).

- Entrada solemne [y bendición de palmas $]^{34}$ (Domingo de Ramos) en el caso de no poder celebrarse la procesión.

- Domingos del tiempo Pascual. ${ }^{35}$

27 El Bendicional prevé diversas formas.

28 La hermosa tradición infantil conviene fomentarla animando a los más pequeños de la casa a escribir con tiza en las puertas la cifra del año recién comenzada y las letras C+ M+ B que en latín son el inicio de los nombres de los magos y de la jaculatoria: Christus Mansionem Benedicat (Cristo bendiga esta casa).

29 Este rito pertenece al día de Epifanía (“Día de las luces”). Se propone como dominical cuando la solemnidad se celebra en el domingo más cercano. El anuncio se realiza inmediatamente después de la proclamación del Evangelio y antes de la homilía.

$30 \mathrm{Al}$ comienzo de la celebración en sustitución del Acto penitencial. El sacramento del Bautismo tras la homilía.

31 Al comienzo de la celebración en sustitución del Acto penitencial.

32 Los del ciclo A son domingos catecumenales; los del B, son cristológicos; y, los del $\mathrm{C}$, son penitenciales. El primero y segundo tienen una temática fija: lucha contra Satanás y victoria de la luz. Del tercero al quinto según el ciclo, pero si hubiera catecúmenos siempre los del ciclo A con la triple temática catequética: agua, luz y vida; por el agua somos iluminados (Fos) para tener vida eterna (Zoé).

33 Siguiendo el Ritual de la Iniciación Cristiana de Adultos.

34 Ídem.

35 El tiempo pascual es una semana de semanas. Los Domingos de la Cincuentena presentan los grandes temas kerigmáticos: Resurrección, Apariciones del Viviente mostrando su identidad (Yo soy... Pastor, Puerta, Vid, Pan de vida, Cordero / León, etc.), Ascensión y Pentecostés. Son domingos para iniciar o consolidar el Oficio de Vísperas / adoración eucarística. La víspera de los domingos de la Cincuentena podría rezarse la devoción dominical del "ViaLucis". En Cuaresma, además del domingo, se acentúa el viernes; en la Cincuentena toda la atención recae sobre el 
- Aspersión solemne con el agua consagrada en la Vigilia Pascual ${ }^{36}$ (Domingo de Resurrección).

- El canto solemne del Aleluya durante los siete domingos de la Cincuentena. ${ }^{37}$

- Celebración del sacramento de la Santa Unción ${ }^{38}$ (VI Domingo de Pascua).

- Vigilia [Lucernario / ofrenda del incienso] ${ }^{39}$ del Domingo de Pentecostés.

- Bendición y aspersión del agua ${ }^{40}$ (Domingo de Pentecostés).

- Apagado del Cirio pascual y traslado al baptisterio ${ }^{41}$ (Domingo de Pentecostés).

- Domingo de la Santa Trinidad (oración por la vida monástica / religiosa / vírgenes consagradas, eremitas, etc.).

- Exposición del Santísimo ${ }^{42}$ (Domingo del Cuerpo y Sangre de Cristo).

Otros domingos que pueden subrayarse con moniciones, intenciones en la Oración Universal (Preces), colectas económicas especiales o con la Plegaria Eucarística para Misas por diversas necesidades podrían ser: Jornada por la Unidad de los cristianos, Campaña contra el hambre, Vocaciones, Misiones, Pobres, Iglesia perseguida, Orientales, domingo de la Biblia (difusión de la Palabra de Dios, entrega de la Palabra, despedida con el

domingo ya desde sus primeras Vísperas. Estos son los domingos sacramentales por excelencia: Confirmación, Primera Comunión, Unción, etc.

No se celebra a los santos en estos domingos y conviene sustituir el Acto Penitencial.

36 Ídem.

37 El tiempo de "Pentecostés" o Cincuentena es el tiempo caracterizado por este canto pascual que ha de resaltarse, especialmente, en sus domingos.

38 La celebración del sacramento del sacramento tras la homilía.

39 Cuando la Misa de Pentecostés, en la víspera, se celebra de forma vigiliar.

$40 \mathrm{Al}$ comienzo de la celebración en sustitución del Acto penitencial.

${ }_{41}$ Este gesto devocional, como clausura de la Cincuentena, puede hacerse tras una monición al final de la celebración.

42 Conviene tras la misa de la solemnidad exponer el Santísimo Sacramento, durante un tiempo oportuno, para la adoración de los fieles. Es oportuno recordar que no se puede exponer el Sacramento solo para impartir la bendición. 
beso de la Biblia, etc.), Domingo de inicio del año escolar / académico / catequético, etc. ${ }^{43}$

\section{Viviendo según el domingo}

La participación en la Misa dominical, cuando es auténtica, cambia nuestras vidas, nos hace pasar de la celebración del primer día a una vivencia nueva de cada día de la semana que nace del domingo.

Esta novedad radical que la Eucaristía introduce en la vida del hombre ha estado presente en la conciencia cristiana desde el principio. Los fieles percibieron en seguida el influjo profundo que la celebración eucarística ejercía sobre su estilo de vida. San Ignacio de Antioquía expresaba esta verdad definiendo a los cristianos como «los que han llegado a la nueva esperanza», y los presentaba como los que viven «según el domingo» (iuxta dominicam viventes). Esta fórmula del gran mártir antioqueno pone claramente de relieve la relación entre la realidad eucarística y la vida cristiana en su cotidianidad (SC, n. 72).

\section{Esta expresión —vivir según el domingo—,}

[...] subraya también el valor paradigmático que este día santo posee con respecto a cualquier otro día de la semana. En efecto, su diferencia no está simplemente en dejar las actividades habituales, como una especie de paréntesis dentro del ritmo normal de los días. Los cristianos siempre

43 "Las Jornadas eclesiales de oración o con otros fines en los domingos y fiestas de precepto, de suyo no oscurecen la importancia de la celebración del día del Señor o de la memoria de la Santísima Virgen y de los Santos. Junto al misterio o aspecto que la Iglesia celebra, que ha de estar en el centro del domingo o de la fiesta de precepto, las Jornadas extienden este aspecto hacia la misión de la Iglesia y la vida comunitaria y espiritual de los fieles. Pero se requiere para esto que las Jornadas se adapten a los textos litúrgicos propuestos en el Leccionario y en el Misal y no traten de polarizar la celebración. En muchos casos será suficiente anunciar el motivo de la Jornada en la monición introductoria o referirse a él en la homilía, y realizar la correspondiente intención en la Oración de los Fieles, o indicar oportunamente la finalidad de la colecta" (Conferencia Episcopal Espańola, 1992, n. 42). 
han vivido este día como el primero de la semana, porque en él se hace memoria de la radical novedad traída por Cristo. Así pues, el domingo es el día en que el cristiano encuentra aquella forma eucarística de su existencia que está llamado a vivir constantemente. «Vivir según el domingo» quiere decir vivir conscientes de la liberación traída por Cristo y desarrollar la propia vida como ofrenda de sí mismos a Dios, para que su victoria se manifieste plenamente a todos los hombres a través de una conducta renovada íntimamente" (SC, n. 72).

La relación con el domingo no es algo coyuntural en la vida cristiana sino radical y existencial; de ahí, el interés por recordar el "precepto dominical" ${ }^{4}$. La participación en la eucaristía dominical es un indicativo de la temperatura de la fe, ya que:

Perder el sentido del domingo, como día del Señor para santificar, es síntoma de una pérdida del sentido auténtico de la libertad cristiana, la libertad de los hijos de Dios. A este respecto, son hermosas las observaciones de [... San] Juan Pablo II en la Carta apostólica Dies Domini a propósito de las diversas dimensiones del domingo para los cristianos: es diez Domini, con referencia a la obra de la creación; dies Christi como día de la nueva creación y del don del Espíritu Santo que hace el Señor Resucitado; diez Ecclesiae como día en que la comunidad cristiana se congrega para la celebración; diez hominis como día de alegría, descanso y caridad fraterna (SC, n. 73).

Desarrollando esta última perspectiva, que nos pone en relación con la existencia de todos los seres humanos, conviene recordar la importancia del descanso. La historia para que este fuese reconocido por las legislaciones

44 El reunirnos todos, en un mismo lugar, para celebrar los santos misterios es responder al Padre celeste que llama a sus hijos para estrecharlos consigo por Cristo, en el amor del Espíritu Santo. La Eucaristía no es una acción privada, sino la acción del mismo Cristo que asocia siempre a sí a la Iglesia, con un vínculo esponsal indisoluble (Cfr. Mane nobiscum Domine, cap. III). En la liturgia de la Palabra escuchamos la misma Palabra divina, signo de comunión entre todos aquellos que la ponen en práctica. En la liturgia eucarística presentamos, junto con el pan y el vino, la ofrenda de nuestra vida: es la común ofrenda de la Iglesia que en los santos misterios se dispone a hacer comunión con Cristo. 
ha mostrado un itinerario de convencimiento sobre la importancia de coincidir en un día común, de encuentro familiar y de asueto para el cuerpo y el espíritu.

En efecto, los cristianos, en cierta relación con el sentido del sábado en la tradición judía, han considerado el día del Señor también como el día del descanso del trabajo cotidiano. Esto tiene un significado propio, al ser una relativización del trabajo, que debe estar orientado al hombre: el trabajo es para el hombre y no el hombre para el trabajo. [...] Es indispensable que el hombre no se deje dominar por el trabajo, que no lo idolatre, pretendiendo encontrar en él el sentido último y definitivo de la vida». En el día consagrado a Dios es donde el hombre comprende el sentido de su vida y también de la actividad laboral (SC, n. 74). ${ }^{45}$

La Eucaristía hace la Iglesia y la propia celebración dominical espolea a cada miembro de la asamblea y a la comunidad toda hacia el ejercicio de la auténtica caridad: la oblación o entrega. El último saludo de la Misa (Dominus vobiscum) es el más difícil porque supone reconocer que el Señor está no solo en la comunidad eclesial reunida, en la Palabra proclamada, en el Pan y el Vino eucaristizados y cambiados de realidad. Reconocer la presencia del Señor fuera de la celebración es también compromiso de ser solidarios y de compartir los bienes; es decir, suponen el esfuerzo por reconocer a Cristo en el mundo donde no es inmediatamente reconocible. ${ }^{46}$

Una vez más resuena la pregunta que aparecía en Mane nobiscum Domine: ¿Por qué no hacer de [este...] un tiempo en el que las comunidades diocesanas y parroquiales se comprometan especialmente a afrontar con

45 Véase: D.A. Carson (ed.) (2013), Dallo Sabbath al giorno del Signore Un’indaginebiblica, storica e teológica.

46 "La caridad fraterna y la solidaridad con los necesitados, en cualquiera de las formas que pueda adoptar, desde la oferta de dinero en la colecta que se hace durante la presentación de los dones del pan y del vino en la Misa, hasta los gestos o compromisos más persistentes en favor de los pobres o de los marginados, constituyen sin duda uno de los signos más evidentes de la participación profunda en el Sacrificio eucarístico y una de las señales más eficaces que abren el camino a la acción evangelizadora " (Conferencia Episcopal Española, 1992, n. 31). 
generosidad fraterna alguna de las múltiples pobrezas de nuestro mundo? (Cfr. n. 28). Esto es hacer del "señor de los días" el día de la caridad. ${ }^{47}$

\section{Propuestas operativas}

Al socaire de aquellas interesantes Sugerencias y Propuestas de la Santa Sede (n. 35), ya citadas, apuntamos algunas ideas pastorales que pueden dar un tono a nuestros domingos:

- $\quad$ Por lo que a las <comunidades parroquiales> se refiere la primera propuesta es dar a la Eucaristía dominical el puesto central que le compete en la vida parroquial, con razón llamada «comunidad eucarística» (cf. SC 42; Mane nobiscum Domine, 23; DiesDomini, 35-36; Eucharisticum mysterium, 26).

- Donde sea necesario, reordenar o dar una disposición estable a los lugares de la celebración (altar, ambón, sede) y a la reserva de la Eucaristía (sagrario, capilla de la adoración); dotarse de los libros litúrgicos dignos; cuidar la autenticidad y la belleza de los signos tales como vestiduras, vasos sagrados, decoración ${ }^{48}$ ).

Incrementar, o si no lo hay, instituir el Grupo litúrgico parroquial. Cuidado de los ministros instituidos y de los ministros extraordinarios de la Comunión, de los ministros, de la schola cantorum, etc.

- Dar una atención especial al canto litúrgico, que sea auténticamente confesante de la fe y que se enseñen los salmos dominicales más importantes.

- Programar durante algunos periodos del año encuentros formativos específicos sobre la Eucaristía en la vida de la Iglesia y del cristiano; ocasión particularmente propicia para adultos y niños es el tiempo de

47 "Este día santo del Señor es, pues, memorial del Señor. Es por lo que se llama día dominical, porque es el Señor de los días [...] Este día particular es para nosotros la fuente de toda buena acción” (Eusebio de Alejandría, Sermón 16, PG 86, 461).

48 Recordando a aquel sacristán que decía a los que traían flores artificiales: "Las flores de plástico son para los cementerios no para la Misa. ¿Decoraría Vd. la mesa festiva de su casa con ellas?". 
preparación para los sacramentos de la Confirmación y de la Primera Comunión.

- Leer y dar a conocer la tercera edición de la Ordenación General del Misal Romano y la Introducción del Orden de las Lecturas de la Misa; el Ritual — gran desconocido- "Sobre la sagrada Comunión y el culto del misterio eucarístico fuera de la Misa”; la encíclica Ecclesia de Eucharistia y la instrucción que le siguió Redemptionis Sacramentum; programar el estudio de la Exhortación Sacramentum Caritatis y las enseñanzas catequéticas del Papa Francisco sobre la Misa.

- Enseñar a «estar en la Iglesia»: qué se debe hacer al entrar; agua bendita; genuflexión o reverencia profunda ante el Santísimo Sacramento; clima de recogimiento; indicaciones para ayudar a una participación más interiorizada de la Misa, especialmente en algunos momentos (tiempos de silencio, oración personal después de la comunión) y para educar a la participación exterior (modo de aclamar o de pronunciar coralmente las partes comunes). Fomentar la comunión bajo las dos especies según la normativa vigente (Cfr. SC, n. 55; IGMR, nn. 281287; Redemptionis Sacramentum, nn. 100-107).

- Celebrar convenientemente el aniversario de la Dedicación de la propia iglesia. Si no se puede en el día propio en un domingo más cercano del Tiempo Ordinario.

- Redescubrir la propia iglesia parroquial, conociendo el sentido de cuanto en ella habitualmente se ve: lectura guiada del altar, del ambón, del tabernáculo, iconografía, vidrieras, portales, etc. El aspecto visible de la iglesia favorece la contemplación del Invisible.

- Promover el culto eucarístico y la oración personal o comunitaria delante del Santísimo (Cfr. Mane nobiscum Domine, 18): visita, adoración del Santísimo y bendición eucarística, etc. Es una magnífica propuesta para la tarde del domingo.

- Tras las primeras Vísperas del domingo — sábado tarde — proponer en circunstancias especiales iniciativas específicas (vigilias de adoración nocturna).

- Verificar la regularidad y la dignidad de la distribución de la comunión a los enfermos tras la misa dominical para que se sientan partícipes de la alegría en el día de la comunidad. ${ }^{49}$

49 Si bien no es un tema específicamente dominical es fundamental dar a conocer la enseñanza de la Iglesia sobre el Viático ( $C f r$ r. Catecismo, nn.1524ss). 
- Acompañar la vida espiritual de quienes, participando en la santa Misa, no pueden recibir la comunión por vivir en situación irregular.

Asimismo, dado el estrecho vínculo entre Eucaristía y «vida consagrada», el tema que estamos tratando debe resultar un estímulo más para profundizar en el corazón de la propia vocación y misión, personal y comunitariamente. Dado que en todas las Reglas y Constituciones está prescrita o recomendada la Misa cotidiana y la devoción eucarística, vamos a ver cómo esto se une al tema del domingo y a las Sugerencias de la Sede Apostólica (n. 37). En este sentido, algunas sugerencias de reflexión y de revisión pueden ser:

- Sobre la calidad de la celebración eucarística en comunidad.

- Sobre la fidelidad a las normas litúrgicas.

- Sobre la herencia eucarística de la tradición del propio Instituto.

- Sobre la situación presente.

- Sobre la devoción eucarística personal.

- Sobre la inserción de los laicos a la liturgia conventual.

Además, algunas acciones concretas de revisión pueden ser:

- $\quad$ Redescubrir en la vida y en los escritos de los propios fundadores/as la piedad eucarística practicada y enseñada por ellos.

- Preguntarse: ¿qué testimonio de vida ofrecen las personas de vida consagrada que trabajan en parroquias, hospitales, enfermerías, instituciones educativas y escolásticas, penitenciarias, centros de espiritualidad, asilos, santuarios, monasterios, etc.?

- Verificar si se sigue la orientación dada por el Magisterio en repetidas ocasiones (Cfr. Dies Domini, n. 36) de participar en la Misa dominical de la parroquia y de adaptarse bien con la pastoral de la Iglesia diocesana en la que viven.

- Incrementar horas de adoración al Santísimo Sacramento (Cfr. Mane nobiscum Domine, n. 18) la tarde del domingo en "las casas religiosas".

- Asegurar en todas las comunidades monásticas y religiosas realizar en la tarde del domingo el Oficio de Vísperas, invitando, con horarios visibles, al pueblo cristiano.

Las SP de la Sede Apostólica recuerdan que el espíritu de comunión, fraternidad y caridad que motiva la incorporación a una "Asociación, Hermandado Movimiento está naturalmente ligado al misterio eucarístico 
(n. 39). Existen fraternidades y asociaciones explícitamente dedicadas a la Eucaristía, al Santísimo Sacramento, a la devoción eucarística y a su consecuencia: la caridad hacia los más pobres. Aquí se debe subrayar la relación Domingo-Eucaristía. Algo importante: la introducción de asociaciones, grupos y movimientos en la Iglesia, que contribuyen a su edificación y vitalidad, según sus carismas, se manifiesta con el encuentro ordinario en las misas dominicales de la parroquia (Cfr. Mane nobiscum Domine, n. 23; Dies Domini, n. 36).

\section{Conclusión}

Vivir en tiempo presente reavivando en todas las comunidades la celebración de la Eucaristía dominical debería ser la primera tarea de nuestras comunidades parroquiales (Cfr. Mane nobiscum Domine, 23 y 29).${ }^{50}$ Como se propuso, en el no lejano Año de la Eucaristía, si al menos se lograra reavivar la celebración eucarística acentuando la peculiaridad dominical, valorando más la Plegaria Eucarística, junto con el incremento de la adoración tras la Misa y el compromiso con los necesitados, habremos realizado una enorme tarea de catequesis y evangelización en nuestras comunidades que en cada domingo celebran el misterio eucarístico.

Por eso, los esfuerzos académicos como el Encuentro Internacional de Liturgia de la Facultad de Teología de la Universidad Pontificia Bolivariana (Medellín):

- Es una invitación a reflexionar, constatar, interiorizar, actualizar eventualmente los Estatutos tradicionales e insertar la teología bíblica y eucarística del día del Señor.

- Es una ocasión para una profundización catequético-mistagógica de la Eucaristía y del día del Señor (escuela dominical).

50 Véase también: G. Liberto (2015), Le gocce del tempo - Riflessioni sui ritmi del settimo giorno. 
- Es un estímulo para dedicar más tiempo a la adoración eucarística, involucrando también otras a personas en un tipo de "apostolado" eucarístico.

- Es una invitación a enlazar la oración y el compromiso de caridad en encuentros dominicales con familias, grupos o comedores de caridad.

\section{Referencias}

Botte, B. (1990). Las denominaciones del domingo en la tradición cristiana. Cuadernos Phase 24: 11-32.

Castellano, J. (1992). La espiritualidad del domingo. Teología, mistagogía, compromiso. Cuadernos Phase 192: 475-490.

CONALI (2016). "Celebrar la Misericordia Comentarios a la Plegaria eucarística de la Reconciliación I”. Boletín de información, servicios y coordinación nacional de liturgia 146 (marzo). Disponible en: http://www.iglesia.cl/conali/boletin/ conali_146.pdf.

Conferencia Episcopal Española (1992). Sentido evangelizador del domingo y de las fiestas. Instrucción. Madrid.

Concilio Vaticano II. Constitución Apostólica Sacrosantum Concilium.

Congregación para el Culto Divino (2005). Sugerencias y Propuestas, ante la celebración del Año de la Eucaristía.

Carson, D.A. (ed.) (2013). Dallo Sabbath al giorno del Signore - Un'indagine biblica, storica e teológica. Florencia: Collana Approfondimenti.

Danielou, J. (1990). El domingo como octavo día. Cuadernos Phase 24: 33-61.

Eusebio de Alejandría. Sermón 16 sobre el día del Señor, PG 86, 461.

Fernández Caballero, F. (2000). Celebrar el domingo. Perspectivas trinitarias del día del Señor. Salamanca: Secretariado Trinitario.

Florio, G. (2013). La domenica - Perché andiamo a celebrare?. Bolonia: EDB.

Giraudo, C. (2012). La Plegaria Eucarística. Culmen y fuente de la divina liturgia. Salamanca: Ediciones Sígueme. 
González López-Corps, M. (2009). La acción de Dios en el Año litúrgico. En M. Del Campo Guilarte (ed.), La pedagogía de la fe al servicio del itinerario del Iniciación Cristiana. Madrid: S. Dámaso. 297-310.

Juan Pablo II (31 mayo 1998). Carta Apostólica Dies Domini.

Juan Pablo II (17 abril 2003). Carta Encíclica Ecclesia de Eucharistia.

Juan Pablo II (7 octubre 2004). Carta Apostólica Mane nobiscum Domine.

Liberto, G. (2015). Le gocce del tempo - Riflessioni sui ritmi del settimo giorno, Roma: Lib. Ed. Vaticana.

López Martín, J. (1998). Los domingos con intenciones especiales. Cuadernos Phase 28: 137-140.

Vatican.va (17 de marzo de 2003). Ordenación General del Misal Romano. Ciudad del Vaticano. 